\title{
Comparison of acceptability of and preferences for different methods of measuring blood pressure in primary care
}

Paul Little, Jane Barnett, Lucy Barnsley, Jean Marjoram, Alex Fitzgerald-Barron, David Mant

Primary care $\mathrm{p} 254$

Community

Clinical Sciences

Division (Primary

Medical Care

Group), Faculty of

Medicine, Health

and Biological

Sciences,

Southampton

University,

Aldermoor Health

Centre,

Southampton

SO16 5ST

Paul Little

MRC clinician

scientist

Jane Barnett

research nurse

Lucy Barnsley

medical student

David Mant

professor

Nightingale

Surgery, Greatwell

Drive, Romsey

SO51 7QN

Jean Marjoram

practice nurse

St Clements

Surgery, Winchester

SO23 8AD

Alex

Fitzgerald-Barron

general practitioner

Correspondence to:

P Little

psl3@soton.ac.uk

BMJ 2002;325:258-9
Blood pressure is probably the most common measurement used in clinical practice and the most common reason for initiation of long term treatment. Recent guidelines for the use of ambulatory monitoring of blood pressure recommend its use in both initial diagnosis (before starting treatment) and assessing control. ${ }^{1}$ If ambulatory monitoring is to be used more often we need evidence about its acceptability. Anecdotal reports of its acceptability exist, ${ }^{23}$ and one large study found that the major drawback was sleep disturbance. ${ }^{4} \mathrm{It}$ is not clear if patients regard such inconvenience and disturbance as worth while to obtain accurate readings or what patients feel about the alternatives. One study of home blood pressure monitoring suggested that patients found it acceptable. ${ }^{5}$ No study has yet explored the main issues for patients about the acceptability of the different methods of measuring blood pressure or compared the acceptability of all the available methods.

\section{Methods and results}

We recruited 200 patients from three practices; all had newly diagnosed essential hypertension or established

Rating of different methods of measuring blood pressure. Values are median (interquartile range) and mean unless stated otherwise

\begin{tabular}{|c|c|c|c|c|c|}
\hline & Home $(n=153)$ & $\begin{array}{l}\text { Self measurement in } \\
\text { surgery }(n=63)\end{array}$ & Ambulatory $(n=156)$ & Nurse $(n=153)$ & Doctor $(n=152)$ \\
\hline \multicolumn{6}{|l|}{ Disturbance and discomfort } \\
\hline It made me anxious & 2 (2 to 5$) ; 3.2$ & 5 (2 to 5$) ; 3.8$ & 2 (2 to 5$) ; 3.3$ & 3 (2 to 5$) ; 3.4$ & 4 (2 to 5$) ; 3.7$ \\
\hline $\begin{array}{l}\text { It disturbs home life or everyday } \\
\text { activities }\end{array}$ & 2 (2 to 5); 3.2 & 2 (2 to 4$) ; 3.1$ & 4 (2 to 5$) ; 3.9$ & 2 (2 to4); 3.0 & 2 (2 to 4$) ; 3.0$ \\
\hline It disturbs sleep & 2 (2 to 4$) ; 3.0$ & 2 (2 to 4$) ; 2.5$ & 5 (2 to 6$) ; 4.3$ & $2(2$ to 4$) ; 2.7$ & $2(2$ to 4$) ; 2.7$ \\
\hline It disturbs work & 3 (2 to 4$) ; 3.1$ & 3 (2 to 4$) ; 3.2$ & $4(2$ to 5$) ; 4.0$ & 4 (2 to 4$) ; 3.3$ & 3 (2 to 4$) ; 3.2$ \\
\hline I was uncomfortable & 2 (2 to 4$) ; 3.2$ & 2 (2 to 3 ); 2.5 & 5 (2 to 6$) ; 4.2$ & 2 (2 to 3 ); 3.6 & 2 (2 to 3$) ; 2.5$ \\
\hline \multicolumn{6}{|l|}{ Self consciousness } \\
\hline I felt self conscious & 2 (1 to 2$) ; 2.3$ & 2 (2 to 3$) ; 2.6$ & 2 (2 to 5$) ; 3.2$ & 2 (2 to 3.25$) ; 2.5$ & 2 (2 to 3.75$) ; 2.6$ \\
\hline \multicolumn{6}{|l|}{ Uncertainty } \\
\hline I felt unsure what to do & 2 (1.25 to 2.75$) ; 2.4$ & 2 (2 to 3$) ; 2.6$ & 2 (2 to 2$) ; 2.2$ & 2 (2 to 4$) ; 2.5$ & 2 (2 to 3$) ; 2.5$ \\
\hline There is a lot of waiting around & $2(2$ to 4$) ; 2.8$ & 2 (2 to 4$) ; 2.7$ & 2 (2 to 4$) ; 2.9$ & 2.5 (2 to 5$) ; 3.3$ & $4(2$ to 5$) ; 3.7$ \\
\hline $\begin{array}{l}\text { It worried me knowing the blood } \\
\text { pressure }\end{array}$ & 2 (2 to 5 ); 2.9 & $2(2$ to 4$) ; 2.7$ & 2 (2 to 4$) ; 2.8$ & 2 (2 to 5$) ; 3.0$ & 2 (2 to 5$) ; 3.0$ \\
\hline It was difficult to remember to do it & 2 (2 to 3 ); 2.6 & 2 (2 to 3$) ; 2.5$ & 2 (2 to 4$) ; 2.4$ & 2 (2 to 4$) ; 2.6$ & $2(2$ to 4$) ; 2.5$ \\
\hline \multicolumn{6}{|l|}{ Accuracy } \\
\hline $\begin{array}{l}\text { It was worth the trouble to get } \\
\text { accurate readings }\end{array}$ & 6 (6 to7); 6.2 & $6(6$ to 7$) ; 5.9$ & 6 (6 to 7$) ; 6.2$ & $6(6$ to 7$) ; 6.1$ & $6(6$ to 7$) ; 6.1$ \\
\hline \multicolumn{6}{|l|}{ Control and efficiency } \\
\hline I felt in control & $6(6$ to 6$) ; 5.7$ & 6 (5 to 6$) ; 5.4$ & 6 (4 to 6$) ; 5.2$ & $5(4$ to 6$) ; 4.9$ & 5 (4 to 6$) ; 4.6$ \\
\hline $\begin{array}{l}\text { It is a good way to use or save } \\
\text { doctor or nurse time }\end{array}$ & 6 (6 to 7$) ; 5.8$ & 6 (6 to 7$) ; 5.9$ & 6 (6 to 7$) ; 5.8$ & 6 (4 to 6$) ; 5.3$ & 5 (4 to 6$) ; 4.8$ \\
\hline \multicolumn{6}{|l|}{ Analysis } \\
\hline Mean (SD) item score* & $2.67(0.90)$ & $3.58(0.48)$ & $3.88(0.82)$ & $3.47(0.70)$ & $3.45(0.79)$ \\
\hline $\begin{array}{l}\text { Difference in mean item score }(95 \% \\
\mathrm{Cl}) \text { compared with ambulatory } \\
\text { monitoring } \dagger\end{array}$ & $-1.28(-1.10$ to -1.46$)$ & $-0.41(-0.18$ to -0.65$)$ & Not applicable & $-0.45(-0.31$ to -0.59$)$ & $-0.48(-0.34$ to -0.61$)$ \\
\hline Ranking by patient $\ddagger$ & 1 (1 to 2$) ; 1.7$ & $3(2$ to 4$) ; 3.0$ & 4 (2 to 4$) ; 3.2$ & 2 (2 to 3$) ; 2.4$ & $3(2$ to 3$) ; 2.7$ \\
\hline $\begin{array}{l}\text { Rated as "best measurement for } \\
\text { them" by patients (\%) }\end{array}$ & $67 / 154(44)$ & $2 / 52(4)$ & $27 / 154(18)$ & $36 / 154(23)$ & $16 / 154(10)$ \\
\hline
\end{tabular}

hypertension with poor control. We measured blood pressure in all patients by repeated measurements by a nurse, home measurement, ambulatory monitoring, and measurement by a doctor. We also invited the final 70 patients to take their own blood pressure in a room provided in the practice (see $\mathrm{p} 000$ ).

Two focus groups of patients who had experienced the different methods generated issues to be included in the questionnaire (table). Each group comprised seven or eight people, with a balance of younger $(<60)$ and older patients, men and women, and manual and non-manual socioeconomic groups. A preliminary questionnaire to 60 consecutive patients confirmed that all the issues identified were felt to be important by most patients (except "knowing the blood pressure worries me").

The overall mean "problem" score for each measurement (the mean item score) was internally reliable (Cronbach's $\alpha=0.85$ ) and approximately normally distributed. We compared measurements by using analysis of variance for repeated measures and the Bonferroni correction for post hoc comparisons. 
We assessed the test-retest reliability after one month in 23 consecutive patients; $77 \%$ of the Spearman's $r$ values for individual items were $\geqslant 0.50$, and no item performed badly $(r \leqslant 0.50)$ for more than two of the different methods of blood pressure measurement.

Patients felt that all methods were worth the trouble to get accurate measurements. Methods differed significantly in their overall "problem" score (ambulatory, home, doctor, and nurse ( $\mathrm{n}=145), F=193$, $\mathrm{P}<0.001$; including self measurement in surgery $(\mathrm{n}=56) \quad F=81, \mathrm{P}<0.001)$. The scoring of ambulatory monitoring for discomfort and disturbance of life and sleep explains why its overall score (the mean of all the items) was significantly higher than those for the other methods. Home readings performed significantly better than all the other methods in the overall score and were also ranked highest by most patients.

\section{Comment}

The important issues identified in this study support the limited previous reports about the acceptability of various methods of blood pressure measurement..$^{2-5}$ Patients rated most methods as causing few problems and being worth the trouble to get accurate readings. Few patients regarded measurement by a doctor as the most acceptable method. Ambulatory monitoring performed less well than other methods, largely owing to discomfort and disturbance of life and sleep; there may be a trade off between the accuracy of ambulatory monitoring and its acceptability. Overall, home measurements may be the most promising option, as they are the most acceptable method to patients and were preferred to either readings in the surgery or ambulatory monitoring.

We thank the doctors, staff, and patients at Aldermoor Health Centre, Nightingale Surgery, and St Clements Surgery. We also thank Eoin O'Brien for advice and helpful comments. DM is now employed at the Division of Public Health and Primary Care, Institute of Health Sciences, Oxford OX3 7LF.
Contributors: PL and AFB had the original idea for the study. All authors contributed to the development of the protocol.JB, JM, and LB ran the study on a day to day basis. PL and LB performed the analysis. All authors contributed to writing the paper. PL is the guarantor of the study.

Funding: NHS Regional Research and Development grant, and the HOPE charity. PL is funded by the Medical Research Council.

Competing interests: None declared.

1 O'Brien E, Coats A, Owens P, Petrie J, Padfield P, Littler W, et al. Use and interpretation of ambulatory blood pressure monitoring: recommendations of the British Hypertension Society. BMJ 2000;320:1128-34.

2 Cox JP, O'Malley K, O'Brien E. Ambulatory blood pressure measurement in general practice. Br J Gen Pract 1992;42:402-3.

3 Webb DH, Stewart MJ, Padfield PL. Monitoring ambulatory blood pressure in general practice. $B M J$ 1992;304:1442.

4 Beltman F, Heesen W, Smit A, May J, Lie K, Meyboom de Jong B. Acceptance and side effects of ambulatory blood pressure monitoring. evaluation of a new technology. J Hum Hypertens 1996;10(suppl):s39-42.

5 Aylett M, Marples G, Jones K. Home blood pressure monitoring: its effect on the management of hypertension in general practice. $\mathrm{Br} J \mathrm{Gen}$ Pract 1999;49:725-8.

(Accepted 21 March 2002)

\section{Corrections and clarifications}

$A B C$ of clinical electrocardiography: Conditions not primarily affecting the heart

Readers may have been confused by a caption and figure in this article by Corey Slovis and Richard Jenkins (1 June, pp 1320-3). The figure showing short QT interval (in the section "Other non-cardiac conditions," p 1323) was wrongly captioned. The trace indeed showed short QT interval but in a patient with hypercalcaemia [not hypocalcaemia].

Delaying folic acid fortification of flour

We mixed up micrograms and milligrams when inserting some late changes to this editorial by Godfrey P Oakley (8 June, pp 1348-9). In the penultimate sentence of the penultimate paragraph, the concentration given for the recommended fortification of flour with folic acid should be $240 \mu \mathrm{g}$ [not $\mathrm{mg}$ ] folic acid per $100 \mathrm{~g}$ of flour.

\section{Three memorable patients}

\section{Friends in need}

I didn't especially enjoy my year as a preregistration house officer. In fact, I have only three happy memories, and all three patients died. I'm sure that we cured many patients during the year, so it's strange that these successes have all but faded from my memory leaving three distinct faces branded there.

John was in his 70 s with obstructing metastatic bowel cancer, and he slowly deteriorated and then died over the five weeks that I cared for him. His only relative was a brother, and the three of us became quite close, especially as death came to be recognised as inevitable. John was the first patient to die whom I had got to know well, and my feelings were an unfamiliar confusion of sorrow and relief.

Ruth's story was similar in many respects; the only substantial differences were that her cancer was of the lung and her relative a loving daughter.

Finally there was Richard, a middle aged bachelor without friend or family. After an emergency admission for bowel obstruction he was found to have an entirely unsuspected, inoperable colonic cancer. He was an emotionally weak man who,
I feel in retrospect, used me as his friend and support during this desperate point in his life.

Why are these such memorable patients? I mentioned that I was generally unhappy during my preregistration year. In fact, I found the experience very stressful and the responsibility frightening. The leap from carefree student to responsible doctor isn't easy for even the best prepared graduate, and I expect most doctors find that first year to be as traumatic I did.

I'm much happier now, and I can think about these things clearly. When I look back I think these patients were experiencing similar emotions to those that I felt, though to a greater degree. Unhappiness, stress, and fear-I certainly saw these feelings in their eyes, and I suspect that they saw them in mine. At the time, I thought that I had developed friendships with these patients in order to comfort them, but now I believe that we supported each other equally through our very different and yet emotionally similar trials.

So, John, Ruth, and Richard, thank you for happy memories of difficult times. 